\title{
Freight-related greenhouse gas emissions in the supply of spectacle and contact lenses
}

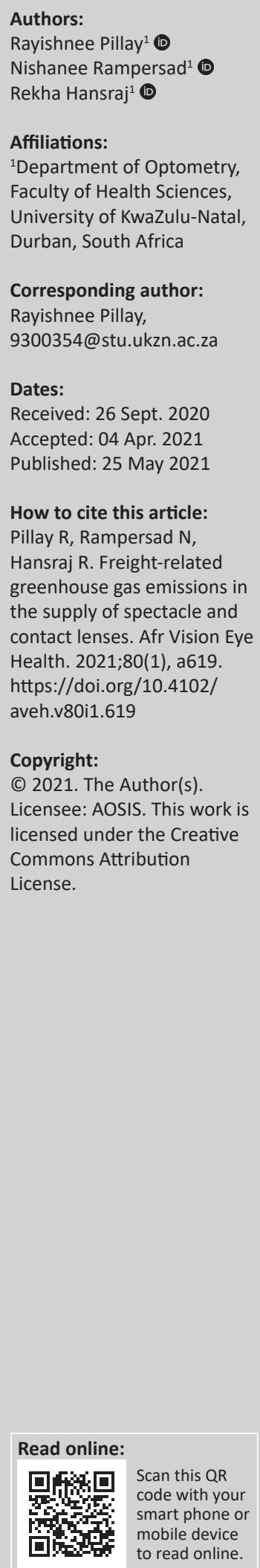

Background: Climate change is a global challenge requiring mitigation from all economic sectors. Although the consequences of climate change are well documented, there are limited studies regarding greenhouse gas emissions generated by the optometric industry.

Aim: This study explored the greenhouse gas emissions created from the freight-related distribution of spectacle and contact lenses to South Africa (SA) in 2019.

Setting: Spectacle and contact lens distributors in SA and an optometric courier service in KwaZulu-Natal.

Methods: Data from a survey completed by lens suppliers and a courier service provider in SA were used in a standardised emissions calculations tool.

Results: The results indicate significant greenhouse gas emissions generated from the distribution of lenses in SA, which is of concern for climate change alleviation goals.

Conclusion: It is recommended that practitioners in the optometric industry, and other healthcare service providers, calculate their emissions data, modify practices to support climate change mitigation and be cognisant of the effect of their practices on the environment.

Keywords: climate change; mitigation; greenhouse gases; freight emissions; optometry; spectacle lenses; contact lenses; freight supply chain; healthcare.

\section{Introduction}

Climate change, a shift in weather patterns due to a rise in global temperature, has been a highly debated topic. ${ }^{1}$ Scientific evidence has confirmed that global climate systems have warmed unprecedentedly since pre-industrial times, ${ }^{2}$ with an increase in average global temperatures of between 0.8 degree Celsius $\left({ }^{\circ} \mathrm{C}\right)$ and $1.2{ }^{\circ} \mathrm{C}$ relative to the pre-industrial period (1850-1900), being attributed to human-related activities. ${ }^{3}$

Climate change intensifies current risks and creates new risks for natural systems, with consequences for humankind as well. ${ }^{3}$ This includes extreme weather events such as severe storm activities, melting of the polar ice sheets and increased rainfall or drought conditions in certain regions. ${ }^{3}$ It may also affect food security, marine and land species redistribution or reduction, contribute to the spread of diseases and affect infrastructure, all of which are expected to have social and economic impacts on the affected communities. ${ }^{3}$ Typically, these risks are disproportionately greater for disadvantaged people and communities. ${ }^{3}$ This presents a challenge that requires an urgent global response ${ }^{2}$ from all economic sectors alike, including the healthcare industry.

The growing economy, rising global population, burning of fossil fuels for energy, change in land use and waste disposal are some of the factors that influence greenhouse gas (GHG) emissions. ${ }^{3}$ Greenhouse gases, such as carbon dioxide $\left(\mathrm{CO}_{2}\right)$, water vapour, nitrous oxides and methane, absorb and emit infrared radiation, and in doing so keep the earth warm enough to sustain growth and life. ${ }^{4}$ Some GHG can remain in the atmosphere for a long time due to its radiative effect; therefore, large increases in GHG emissions can impact global climate systems in the long term. ${ }^{4}$

The longer stringent mitigation action is delayed, the greater the reduction in emissions will need to be in the future. Various countries have signed the Paris Agreement, which aims to restrict average global temperatures to well below $2{ }^{\circ} \mathrm{C}$ from pre-industrial levels, and to devise approaches to restrict increases to $1.5^{\circ} \mathrm{C}$ below the pre-industrial era. ${ }^{5}$ To keep the temperature increase below the recommended $2{ }^{\circ} \mathrm{C}$, the global carbon budget from human-related activities 
needs to be less than 1000 gigatonne $\mathrm{CO}_{2}$ equivalent $\left(\mathrm{GtCO}_{2} \mathrm{e}\right)$ between 2011 and 2100. ${ }^{6}$ Even with scientific warnings and mitigation policy assurances from various countries, GHG emissions have increased about $1.5 \%$ per year in the last decade, reaching a global high of $55.3 \mathrm{GtCO}_{2} \mathrm{e}$ in $2018 .{ }^{7}$ The continuation of current policies would contribute to an average global temperature increase of between $3.4^{\circ} \mathrm{C}$ and $3.7^{\circ} \mathrm{C}$ by 2100 relative to pre-industrial levels. ${ }^{8}$

Much attention has been focused on the major industrial sectors with respect to emissions reporting and alleviation whilst there is limited published research on the contribution to and mitigation of GHG emissions by the healthcare industry. ${ }^{9}$ It is predicted that if international healthcare was a country, it would be the fifth largest emitter on the planet, with a contribution of about $4.4 \%$ of global net emissions. ${ }^{10}$ It was also found that the pharmaceutical industry generates more emissions than the automotive industry. ${ }^{9}$ These emissions are mainly generated from energy consumption, transport and procurement, with almost $71 \%$ of these emissions emanating from supply chain processes. ${ }^{10}$

In the United Kingdom, the carbon footprint of the National Health Service ${ }^{11}$ for 2015 was $22.8 \mathrm{MtCO}_{2} \mathrm{e}$, whilst a study on the carbon footprint of cataract surgery revealed that the supply chain contributed over $50 \%$ of the net emissions. ${ }^{12}$ Healthcare contributed to approximately $11 \%$ of emissions in the United States in 2011, and it is reported that limited data are available to healthcare professionals regarding the environmental impact of the health services they provide. ${ }^{13}$

It has been stressed that environmental sustainability must be considered in the delivery of healthcare, ${ }^{14}$ with suggestions that healthcare professionals should be encouraged to support global strategies to mitigate climate change and strive to reduce the emissions of their own medical practices. ${ }^{15}$ A search of online databases for scientific articles shows a paucity of studies on the emissions generated from the various healthcare fields and auxiliary medical services.

\section{Spectacle lens and contact lens supply in South Africa}

Information on consumer eyewear purchases is collected and compiled by various agencies, with eyewear data including the sales of spectacles, contact lenses (CLs) and sunglasses. ${ }^{16}$ The retail value of eyewear sales in South Africa (SA) increased by approximately 34\% from 2014 to 2019, with a corresponding increase of about $10.8 \%$ in retail volumes for the same period. ${ }^{16}$

It is noteworthy that there are currently no local facilities in SA that manufacture spectacle lenses, CLs or associated products. Lenses and related products are sourced internationally and distributed to optometrists in SA via suppliers who deliver on demand to the optometrists. Internationally based companies have distribution centres in major cities in SA and often have warehouses stocking a pre- determined range of lenses. There are also some South African-owned companies that do not have a wide lens inventory but order products from international suppliers upon request.

There is a long international supply chain distributing products to SA, as lenses and associated care and cleaning products are manufactured in various countries, including China, Thailand, India, the United States, Europe and the United Kingdom. Lens orders are sent to SA either via air or sea freight. The agents based in SA then distribute the products to local optometrists via air and road freight. Often customer demand is time-critical and urgent orders are requested such that suppliers have to air freight the products to meet local needs. Typically, customised lenses are imported from lens manufacturers. This is often 'made-toorder' and could take between two and six weeks to arrive in SA and is described colloquially as a 'back-order'.

There are currently no published studies on the contribution of optometric practices to GHG emissions and the subsequent impact on the environment. The aim of this study was to explore the current freight-related GHG emissions created by the distribution of lenses to optometrists in SA.

\section{Calculation of greenhouse gas emissions}

The Greenhouse Gas Protocol (GHG Protocol) Scope 3 Standard and the GHG Protocol Product Standard are part of a range of widely used international standards to measure and report GHG emissions. ${ }^{17}$ These accounting tools allow companies to assess their GHG emissions along with their supply chain, including the products and services they buy from suppliers and that they sell to customers. ${ }^{17}$ The GHG Protocol reporting standard has three scopes: Scope 1 oversees direct GHG emissions whilst Scopes 2 and 3 concern indirect GHG emissions. ${ }^{17}$ The GHG Protocol Transport tool is a Scope 1 and 3 calculation of GHG emissions from transport or mobile sources used in the distribution of goods. ${ }^{18}$

The Transport Tool calculates $\mathrm{CO}_{2}$, nitrous oxide and methane emissions from the use of vehicles owned by the organisation. ${ }^{18}$ Data required include fuel usage, distances travelled, vehicle type and the weight of goods for freight transport. ${ }^{18}$ The emissions are calculated once these data are input into the tool. Several assumptions may be made when using this tool, based on the available data and the region in review, and this may impact the certainty of the results. ${ }^{18}$ A complete set of data would be ideal when calculating the transport emissions of an organisation; however, it must be noted that some data may be unavailable to the public domain.

\section{Research methods and design}

This study was a cross-sectional design that explored the GHG emissions patterns in the supply of spectacle lenses and CLs in SA in 2019. 


\section{Study population and sampling}

Suppliers providing spectacle lenses and CLs to the South African market were identified from a South African online optometry listing, the 'Optical Assistant'. ${ }^{19}$

A total of 44 lens suppliers in SA were identified from the optometry listing, and contacted via email with a description of the study and a permission letter indicating willingness to participate in the study. The contact details of five suppliers were incorrect on the listing and were further unattainable and were removed from the mailing list. Of the remaining 39 suppliers, those who did not respond to the initial email were sent follow-up emails twice within the subsequent two fortnights.

Thirteen suppliers (nine spectacle lens and four CL) responded positively, indicating a response rate of 33.3\%, and an email with the link to the survey was sent to the contact person. Nine surveys were returned (six spectacle lens and three CL). Two follow-up emails were sent to the four non-responding suppliers, but to no avail. Of the nine returned surveys, three had incomplete information, which could not be verified via further email correspondence, and therefore only six suppliers' responses (four spectacle lens and two CL) were used for this study. Three suppliers responded with information on domestic air freight in addition to international freight data.

Six courier service providers that deliver lenses and associated products to optometrists were also identified from these survey responses and were contacted via email to participate in the survey. One positive response was received and the survey was completed accordingly. The respondent was a well-established courier service provider in the optometric field, with a reported 500 deliveries per day to optometrists in 37 regions within KwaZulu-Natal. There was no response to two subsequent follow-up emails that were sent to the remaining five courier companies in the ensuing fortnight.

The participants requested to remain anonymous and are identified in the study as follows (Table 1):

- Four spectacle lens suppliers: A1, A2, A3 and A4

- Two CL suppliers: B1 and B2

- One optometry-dedicated courier service provider: $\mathrm{C} 1$

Eyewear data for SA as reported by Euromonitor International are supplied within two categories, namely, total eyewear that includes the sales of spectacles, sunglasses, CLs and solutions, incorporating retail store trade for 2019, as well as a separate category for CLs and solutions. ${ }^{16,20}$

In order to provide an indication of the scope of the coverage of the suppliers in this study whilst still maintaining the confidentiality of the respondents, the market share values of some suppliers are reported as percentage intervals of market share in SA in 2019 (Table 1).

\section{Data collection and analysis}

The lens supplier survey requested information on the city or cities the lenses were imported from, weight of the packages and the number of international and local shipments in 2019. The courier service provider survey enquired about road freight data in the KwaZulu-Natal province for 2019. The distance travelled to distribute lenses and weight of the packages as indicated in the survey responses were input in the GHG Protocol Transport Tool $^{18}$ and the emissions generated were automatically computed. These quantitative data were reported in metric tonnes $\mathrm{CO}_{2} \mathrm{e}$.

Where relevant information for the GHG Protocol Transport Tool was insufficient, the following assumptions were made:

- Scope 3 was used, and the region selected was 'Other'.

- Only GHG emissions generated through directinternational air freight to airports in SA in 2019 were calculated.

- The scope of these calculations was limited to freight operations. Other logistics activities, such as warehousing, were not included.

- If the country of manufacture differed from country of air freight to SA, the additional air freight distance from the country of manufacture was not included.

- Fuel usage data are preferable in the GHG Protocol Transport Tool; however, as this information was unavailable, the freight distance and weight were used.

- Road freight in the delivery of lens packages to the respective airports was excluded, and only the flight distance and mean weight of cargo were used in the emissions calculations.

- Suppliers also import products associated with care of spectacle lenses and CLs, like cases and cleaning products. These products are freighted along with the lenses and separation of weight of lenses and care products was not possible and so are included in these calculations.

TABLE 1: Description of survey participants in terms of lens type, average volume of sales, market share value and availability of a written environmental policy.

\begin{tabular}{|c|c|c|c|c|c|}
\hline Supplier & Lens type/service provided & $\begin{array}{l}\text { Average volume of sales } \\
\text { (per month) }\end{array}$ & $\begin{array}{l}2019 \text { SA market share: } \\
\text { Total eyewear }(\%)\end{array}$ & $\begin{array}{l}2019 \text { SA market share: } \\
\text { CL and solutions only (\%) }\end{array}$ & $\begin{array}{c}\text { Written environmental } \\
\text { policy }\end{array}$ \\
\hline A1 & Spectacle lenses & 1000 lenses & $<0.1$ & - & No \\
\hline A2 & Spectacle lenses & 5200 lenses & $<0.1$ & - & No \\
\hline A3 & Spectacle lenses & 60000 lenses & $15-18$ & - & Yes \\
\hline A4 & Spectacle lenses & 150000 lenses & $15-18$ & - & Yes \\
\hline B1 & Contact lenses & 410 lenses & $<0.1$ & $<3$ & No \\
\hline B2 & Contact lenses & 125000 lenses & $0.5-0.7$ & $10-12$ & Yes \\
\hline C1 & Optometry-dedicated courier service & 13000 deliveries & - & - & Yes \\
\hline
\end{tabular}

$\mathrm{CL}$, contact lens; SA, South Africa. 
- Taking into account the size of the Durban port, sea freight emissions calculations were calculated for a small tanker (844 tonnes deadweight).

- Domestic road freight emissions calculations were for 'Light Goods Vehicle-Gasoline, Year- 2005-present'.

- Flight distances between the airports were determined from an online calculator. ${ }^{21}$

- Where suppliers provided a range for weight and number of shipments, the mean of the range was used in the GHG emissions calculation.

- One supplier (A3) indicated most of the international flights to SA originated in China and a few from Thailand; as the number of flights from the latter was unknown, all calculations were determined from China.

\section{Ethical considerations}

This study received ethical approval from the Humanities and Social Sciences Research Ethics Committee at the University of KwaZulu-Natal(Reference:HSS/1649/018D). Gatekeeper permission was sought from the national or regional office of lens suppliers. Upon approval, the survey link was emailed to the contact person. The link directed participants to an information sheet detailing the study, along with informed consent request prior to the survey being accessed. Participants were informed of their right to decline or withdraw at any stage. All participants requested to remain anonymous and were allocated an alphanumeric code to maintain confidentiality. Data were stored in a password-protected computer and were only accessible to the corresponding author. The data will be deleted five years after completion of the study.

\section{Results}

There were seven participants in total (Table 1). Four (A1, A2, A3 and A4) supply spectacle lenses, two (B1 and B2) supply CLs, whilst the final participant (C1) provided an optometrydedicated courier service in the KwaZulu-Natal province.
Four of the internationally based participants (A3, A4, B2 and C1) had written environmental policies, whilst the three South African-owned suppliers did not (A1, A2 and B1).

\section{International freight}

Five participants provided information for international air freight whilst one supplied details for both international air and sea freight (Table 2).

\section{Air freight}

Three participants received air freight from China (A1, A2 and A3) and one from Thailand (A4). One CL supplier (B1) received air freight from the United Kingdom whilst the other (B2) received shipments from the United States of America and the United Kingdom.

Based on findings from the emissions calculator, the average cumulative emissions for the spectacle lens suppliers (A1 to A4) ranged between 2.25 tonnes $\mathrm{CO}_{2} \mathrm{e}$ and 131.794 tonnes $\mathrm{CO}_{2} \mathrm{e}$ in 2019. The South African-owned CL supplier (B1) with annual sales of approximately $5000 \mathrm{CL}$ had an average of three international air freight shipments in 2019 with cumulative GHG emissions of 0.033 tonnes $\mathrm{CO}_{2} \mathrm{e}$ whilst the internationally based CL supplier (B2) with sales of approximately 1.5 million lenses annually had an average of 104 air freight shipments to SA, generating a cumulative 643.24 tonnes $\mathrm{CO}_{2} \mathrm{e}$ in 2019. Total GHG emissions of 807.72 tonnes $\mathrm{CO}_{2} \mathrm{e}$ were generated from the 680 international flights in 2019 for these suppliers (Table 2).

\section{Sea freight}

The spectacle lens supplier (A1) that received shipments via sea freight had a cumulative sea freight GHG emissions of 1.551 tonnes $\mathrm{CO}_{2}$ e for 2019 from three sea freight shipments (Table 2).

The total international freight GHG emissions in 2019 for the six lens suppliers in this study was 809.271 tonnes $\mathrm{CO}_{2} \mathrm{e}$.

TABLE 2a: Greenhouse gas emissions for suppliers' international freight to South Africa for 2019.

\begin{tabular}{|c|c|c|c|c|c|}
\hline $\begin{array}{l}\text { International } \\
\text { freight }\end{array}$ & Supplier & Country of origin & Destination airport & Average number of flights & $\begin{array}{c}\text { Cumulative air freight } \\
\text { GHG emissions } \\
\text { (metric tonnes } \mathrm{CO}_{2} \mathrm{e} \text { ) }\end{array}$ \\
\hline \multirow[t]{7}{*}{$\overline{\text { Air }}$} & A1 & China & Durban & 150 & 2.25 \\
\hline & $\mathrm{A} 2$ & China & Durban & 5 & 22.195 \\
\hline & A3 & China & Johannesburg & 274 & 131.794 \\
\hline & A4 & Thailand & Johannesburg & 144 & 8.208 \\
\hline & B1 & UK & Johannesburg & 3 & 0.033 \\
\hline & & UK & Johannesburg & 52 & 266.5 \\
\hline & Total international air freight & - & - & 680 & 807.72 \\
\hline
\end{tabular}

GHG, greenhouse gas; UK, United Kingdom; USA, United States of America.

TABLE 2b: Greenhouse gas emissions for suppliers' international freight to South Africa for 2019.

\begin{tabular}{|c|c|c|c|c|c|}
\hline $\begin{array}{l}\text { International } \\
\text { freight }\end{array}$ & Supplier & Country of origin & Destination port & $\begin{array}{l}\text { Average number of } \\
\text { shipments }\end{array}$ & $\begin{array}{l}\text { Total sea freight GHG emissions } \\
\text { (metric tonnes } \mathrm{Co}_{2} \mathrm{e} \text { ) }\end{array}$ \\
\hline Sea & $\mathrm{A} 1$ & China & Durban & 3 & 1.551 \\
\hline
\end{tabular}

GHG, greenhouse gas. 
TABLE 3: Greenhouse gas emissions for domestic freight in South Africa for 2019.

\begin{tabular}{|c|c|c|c|c|c|c|c|}
\hline \multirow[t]{2}{*}{ Supplier } & \multicolumn{3}{|c|}{ Air } & \multicolumn{4}{|c|}{ Road } \\
\hline & $\begin{array}{l}\text { From Johannesburg to } \\
\text { destination airport }\end{array}$ & $\begin{array}{l}\text { Average number } \\
\text { of flights }\end{array}$ & $\begin{array}{c}\text { Cumulative air freight } \\
\text { GHG emissions } \\
\text { (metric tonnes } \mathrm{CO}_{2} \mathrm{e} \text { ) }\end{array}$ & Supplier & Province & $\begin{array}{l}\text { Average distance } \\
\text { travelled (km) } \\
\text { (annum) }\end{array}$ & $\begin{array}{l}\text { Total road freight } \\
\text { GHG emissions } \\
\text { (metric tonnes } \mathrm{CO}_{2} \mathrm{e} \text { ) }\end{array}$ \\
\hline A3 & $\begin{array}{l}\text { Eastern Cape, Western Cape, } \\
\text { KwaZulu-Natal }\end{array}$ & 912 & 3.564 & $\mathrm{C} 1$ & KwaZulu-Natal & 288000 & 94.992 \\
\hline A4 & $\begin{array}{l}\text { Eastern Cape, Western Cape, } \\
\text { KwaZulu-Natal }\end{array}$ & 720 & 3.6 & - & - & - & - \\
\hline B2 & $\begin{array}{l}\text { Eastern Cape, Northern Cape, } \\
\text { Western Cape, KwaZulu-Natal }\end{array}$ & 1008 & $0.886 \dagger$ & - & - & - & - \\
\hline Total & - & 2640 & $8.05+$ & - & - & - & - \\
\hline
\end{tabular}

GHG, greenhouse gas.

$\uparrow$, Indicates that figures are rounded.

\section{Domestic freight}

The internationally based suppliers distributed lenses via the regional airports of four major cities in SA. These packages were collected and delivered by a local courier service provider in each city.

\section{Air freight}

The total number of domestic flights for these suppliers in 2019 was 2640 flights. Average cumulative domestic air freight GHG emissions for these suppliers ranged between 0.886 and 3.6 tonnes $\mathrm{CO}_{2} \mathrm{e}$, whilst the total domestic air freight GHG emissions for 2019 was approximately 8.05 tonnes $\mathrm{CO}_{2} \mathrm{e}$ (Table 3).

\section{Road freight}

The courier service provider travelled on average $288000 \mathrm{~km}$ delivering lenses to optometrists in the KwaZulu-Natal province in 2019. The average total GHG emissions for road freight in 2019 was 94.992 tonnes $\mathrm{CO}_{2}$ e (Table 3).

The total GHG emissions from domestic air and road freight in this study for 2019 was 103.042 tonnes $\mathrm{CO}_{2} \mathrm{e}$.

\section{Discussion}

The emissions per capita for SA in 2015 was 9.8 tonnes $\mathrm{CO}_{2} \mathrm{e}$ per person. ${ }^{22}$ This is largely due to an intense reliance on coal for energy production and robust emissions from the transport sector, with the latter alone being 54125.98 gigagram (Gg) $\mathrm{CO}_{2} \mathrm{e}^{22}$ In this study, the cumulative GHG emissions for international freight for the distribution of lenses to SA in 2019 was 809.271 tonnes $\mathrm{CO}_{2} \mathrm{e}$. This is equivalent to the $\mathrm{CO}_{2}$ emissions generated from the consumption of 1874 barrels of oil, and carbon sequestration thereof would require the planting of 13381 tree seedlings over 10 years..$^{23}$ The domestic freight emissions in the delivery of lenses for the same period was 103.042 tonnes $\mathrm{CO}_{2} \mathrm{e}$, which is equivalent to the $\mathrm{CO}_{2}$ emissions from the consumption of 239 barrels of oil, and consequent carbon sequestration would require the planting of 1704 tree seedlings over 10 years. $^{23}$

This study reported the freight-related emissions for six lens suppliers in SA and a courier service provider that distributed lenses in one of the nine provinces in SA. Factoring in the 33 suppliers who did not respond to the invite to participate in the study, the three who provided incomplete information and the optometry-dedicated courier services in the other eight provinces, there would be much higher freight-related GHG emissions for lens distribution in SA in 2019.

The emissions data calculated for these six suppliers are based on several assumptions, which may have resulted in an underestimation of the GHG emissions for lens distribution in SA for 2019. The emissions generated in the transportation of the packages from the manufacturing site or warehouse to the airports, both internationally and locally, were not included. Furthermore, in some instances, products were delivered from a country of manufacture to a country of distribution and then to SA, and the emissions created from the air freight from the manufacturing country was not included. The number of flights and the weight of the deliveries for 2019 were averaged by the suppliers and any variations in these factors would affect the emissions calculation. A fuel-based calculation ${ }^{18}$ would provide more detailed emissions data, but this information was unavailable. Data from more lens suppliers would provide additional insight into the GHG emissions generated by the supply and delivery of lenses to SA.

In comparing the international freight patterns between the spectacle lens suppliers with lower sales volume (A1 and A2), it is noted that A1 used both air and sea freight and had lower freight-related GHG emissions than A2, which only used air freight, with comparable total freight weight. For international freight, switching from air freight to sea freight for less time-critical goods or combining to air-sea freight intermodal shifts can reduce freight emissions. $^{24}$

International freight emissions are recorded but not included in the GHG inventory of an individual country; ${ }^{25}$ therefore, it is possible that international freight emissions may be overlooked whilst attempting to mitigate emissions that are included in the national GHG inventory. It would be advisable for suppliers that source products internationally to review their supply chain emissions and existing organisational structures and consider approaches towards mitigating their GHG emissions.

Domestic freight routes generate approximately 30\% of the total trade-related $\mathrm{CO}_{2}$ emissions, and this is where national 
policies can be implemented to reduce emissions. ${ }^{24}$ Some freight-related options that could help with emissions mitigation include enhancing freight vehicle efficiency, the use of electric vehicles where possible and sustainably produced biofuels, and improving driver behaviour and freight logistics. ${ }^{3,26}$ In 2015, road transport in SA contributed 47681.37 $\mathrm{Gg} \mathrm{CO}_{2} \mathrm{e}$, whilst railway emissions were $611.20 \mathrm{Gg}$ $\mathrm{CO}_{2} \mathrm{e} \cdot{ }^{27} \mathrm{~A}$ shift to a low carbon economy could be promoted by interprovincial modal shifts from carbon-intensive road to rail freight. ${ }^{28}$ The use of rail freight in SA saw a decline after 1988, with the deregulation of road transport. ${ }^{27}$ Plans currently underway to shift freight from road to rail could potentially save 3000 kilotonnes $\mathrm{CO}_{2} \mathrm{e}$, comprising $0.66 \%$ of SA's total mitigation potential. ${ }^{27}$ If these plans are achieved, it would be encouraging for local suppliers as they could then use the national railways for a low carbon rail-road interprovincial mode instead of the current carbon-intensive air-road freight modality.

Typically, the suppliers in this study with larger sales volumes had heavier freight and, consequently, higher GHG emissions. The South African-owned lens suppliers reported lower average sales volumes compared with the internationally based suppliers and generally do not have a local warehouse. They usually order customised lenses for the correction of high ametropia or presbyopia on demand. This type of lens request tends to be time-critical as patients may require their vision corrective device urgently. With lens manufacturing companies being based across the globe, this creates additional pressure on the supplier to deliver, hence the use of air freight for express product delivery.

A promising development in the spectacle lens industry is the introduction of 'additive manufacturing' or threedimensional (3D) printing of spectacle lenses. ${ }^{29}$ Customised spectacle lenses are created from a computer-aided design within a few hours. This may eliminate the need for large lens inventories and decrease logistics and warehousing costs and unplanned international freight for urgent orders whilst saving time and reducing wastage and GHG emissions. ${ }^{30}$ Although the initial start-up costs are currently high, it is anticipated that these prices will decrease in the future and $3 \mathrm{D}$ printing of lenses should become more accessible and affordable. ${ }^{30}$

Optometrists can also play a role in reducing GHG emissions by reviewing their lens order systems. For example, they could encourage a patient to purchase an annual supply of CL and care products instead of smaller orders during the year, thus reducing freight time, as well as collection travel times for the patient. Improving freight logistics is a further option that lens suppliers and optometrists could also consider. ${ }^{24,26}$ Orders that are not time-critical should be stated as such, so the supplier is not pressurised to order via air freight and such orders could be incorporated with planned freight to eliminate additional air freight. Optometrists can minimise urgent orders by educating patients on the environmental consequences so that patients are conscious of the role they play when they request same day or urgent orders. ${ }^{31}$ Where possible, patients should be advised to order CL in advance or have an extra supply to prevent the need for urgent orders.

Sustainability has gained importance in small-to-medium enterprise businesses in France and enforcing proactive environmental decisions, like reducing fuel usage, has resulted in cost-efficiency and lower total carbon emissions. ${ }^{32}$ This indicates that reductions in emissions can be achieved by large and small organisations alike and all organisations should be encouraged to investigate and implement emissions alleviation strategies.

The focus of this study was the GHG emissions in the distribution of lenses to optometrists in SA. However, there are further behaviours that optometrists can adopt to reduce the carbon footprint of their work environment, in addition to reviewing their supply chain. It is advisable to monitor and reduce electricity consumption, in particular air conditioning and switching to alternative or energyefficient renewable sources where possible. ${ }^{33,34}$ Other considerations include the switching off of lights and computers when not in use or after office hours, conserving water, using recycled paper and reducing the need for printing on paper. ${ }^{33,34}$ Waste generation in the work environment can be decreased by eliminating the purchase of single-use and disposable items. ${ }^{34}$ An adjustment in travel routes and times for employees should also be contemplated, possibly by carpooling or travelling out of peak traffic times. ${ }^{34}$ A review of the packaging of lenses and associated products for delivery should also be done to ensure that all plastic packaging is recyclable and is sent for recycling at end-of-life.

Consumers are more aware of the impact of their purchases on the environment and may base their purchases on an organisation's sustainability policies. ${ }^{35}$ If suppliers are proactive about the environmental impact of their products, it may promote product brand value to consumers and have a positive influence on sales. It is recommended that the locally based suppliers who do not have a written environmental policy strive to develop such policies. This can guide their staff regarding sustainability issues and also demonstrate the organisation's awareness and commitment to environmental sustainability.

Approximately $75 \%$ of GHG emissions in many industries result from their supply chains. ${ }^{36}$ Besides additional costs, like carbon taxes, there is also growing consumer awareness of environmental issues, so it is possible for a product brand value to be negatively affected by an organisation's ineffectual sustainability profile. ${ }^{35}$ It is therefore incumbent on the purchaser to examine their supply chains and to balance economy and the environmental cost in business decisionmaking. ${ }^{35}$

Ideally, a full lifecycle assessment (LCA) and product carbon footprint would be required for a better 
understanding of the environmental impact of lenses used in optometry. The information required to complete an LCA is considered business sensitive and was not attainable. The onus is on the individual suppliers to conduct emissions calculations with a standardised tool, in each stage of the product lifecycle, to determine the full impact of their business on the environment and to take appropriate steps to abate any negative effects.

\section{Conclusion}

Even though globalisation of trade has resulted in a hyperconnected world with seemingly limitless consumer choices and access to products, this is expected to be accompanied by an estimated fourfold increase in $\mathrm{CO}_{2}$ emissions from global freight transport between 2010 and $2050 .{ }^{24}$ The associated environmental cost will be detrimental to global climate change mitigation strategies.

Further research with more lens suppliers is warranted, with calculation of a full LCA. It is also recommended that optometrists and their patients review lens order practices. Product choices, supply chain and transport routes can impact environmental outcomes and all role-players should become actively involved in increasing awareness and advocating for positive environmental change.

Achieving climate change goals requires intense mitigation strategies from all economic sectors. In addition to optometry, it is advisable for all healthcare-related professions to take on active roles in measuring and reducing the GHG emissions emanating from their practices.

\section{Acknowledgements Competing interests}

The authors declare that they have no financial or personal relationships that may have inappropriately influenced them in writing this article.

\section{Authors' contributions}

This article forms part of a PhD study in the Discipline of Optometry at the University of KwaZulu-Natal (HSS/1649/018D) being undertaken by R.P., with R.H. and N.R. as the supervisors. All authors were involved in the conceptualisation of the article. R.P. did the literature search and data collection and drafted the research article. R.H. and N.R. were involved in editing of the article to the final version.

\section{Funding information}

This research received no specific grant from any funding agency in the public, commercial or not-for-profit sectors.

\section{Data availability}

The data that support the findings of this study are available from the corresponding aauthor, R.P., upon reasonable request.

\section{Disclaimer}

The views and opinions expressed in this article are those of the authors and do not necessarily reflect the official policy or position of any affiliated agency of the authors.

\section{References}

1. Begley S, Conant E, Stein S, Clift E, Philips M. The truth about denial. Newsweek. 2007;20-29.

2. Intergovernmental Panel on Climate Change. Climate change 2007: The physical science basis. Contribution of Working Group I to the Fourth Assessment Report of the Intergovernmental Panel on Climate Change. Cambridge: Cambridge
University Press; 2007.

3. Intergovernmental Panel on Climate Change. Climate change 2014: Mitigation of climate change. Contribution of Working Group III to the Fifth Assessment Report of the Intergovernmental Panel on Climate Change. Cambridge: Cambridge University Press; 2014.

4. Archer D. Global warming: Understanding the forecast. Oxford: Blackwell Publishing, Ltd; 2007.

5. United Nations Framework Convention on Climate Change. History of the convention [homepage on the Internet]. United Nations Framework Convention
on Climate Change; 2020 [cited 2020 Jun 13]. Available from: https://unfccc. int/process/the-convention/history-of-the-convention\#eq-1; 2020

6. Intergovernmental Panel on Climate Change. Climate change 2014: Synthesis report. Contribution of Working Groups I, II and III to the Fifth Assessment Report of the Intergovernmental Panel on Climate Change. Geneva: IPCC; 2014.

7. United Nations Environment Programme. Emissions gap report 2019 Nairobi: United Nations Environment Programme; 2019.

8. Christensen J, Olhoff A. Lessons from a decade of emissions gap assessments. Nairobi: United Nations Environment Programme; 2019.

9. Belkhir L, Elmeligi A. Carbon footprint of the global pharmaceutical industry and relative impact of its major players. J Clean Prod. 2019;214:18-94. https://doi. org/10.1016/j.jclepro.2018.11.204

10. Health Care Without Harm. Health Care's climate footprint. How the health sector contributes to the global climate crisis and opportunities for action [homepage on the Internet]. Health Care Without Harm; 2019 [cited 2020 Jun 20]. Available from: https://noharm-global.org/documents/health-careclimate-footprint-report

11. Sustainable Development Unit. Carbon footprint update for NHS in England 2015 [homepage on the Internet]. SDU Health; 2016 [cited 2020 Jun 20]. Available from: https://www.sduhealth.org.uk/documents/publications/2016/Carbon_ Footprint_summary_NHS_update_2015_final_v2.pdf

12. Morris DS, Wright T, Somner JEA, Connor A. The carbon footprint of cataract surgery. Eye. 2013;27:495-501. https://doi.org/10.1038/eye.2013.9

13. Alshqaqeeqa F, Esmaeilib MA, Overcash M, Twomeya J. Quantifying hospital services by carbon footprint: A systematic literature review of patient care alternatives. Resour Conserv Recycl. 2020;154:e104560. https://doi. org/10.1016/j.resconrec.2019.104560

14. Royal College of Physicians. Leading for quality: The foundation for healthcare Physicians; 2010 [cited 2020 Jun 13]. Available from: Wiltshire: Royal College of uk/file/271/download

15. Connor A, O'Donoghue D. Sustainability: The seventh dimension of quality in health care. Hemodiallnt.2012;16(1):2-5.https://doi.org/10.1111/j.1542-4758.2011.00652.x

16. Euromonitor International. Eyewear in South Africa. Analysis September 2020 [homepage on the Internet]. Euromonitor; 2020 [cited 2021 Mar 10]. Available from: https://www.euromonitor.com

17. World Resources Institute. GHG protocol. Corporate value chain (scope 3) accounting and reporting standard [homepage on the internet]. World Resources Institute; 2011 [cited 2020 Jun 13]. Available from: http://pdf.wri.org/ghgp

18. World Resources Institute. GHG protocol tool for mobile combustion. Version 2.6 [homepage on the Internet]. World Resources Institute; 2015 [cited 2020 Jun 2]. Available from: https://ghgprotocol.org/calculation-tools

19. SB Media. The optical assistant - May 2019 [homepage on the Internet]. SB Media; 2019 [cited 2019 May 02]. Available from: https://www.sbmedia.co.za/ optical_assistant.php

20. Euromonitor International. Contact lenses and solutions in South Africa. Analysis September 2020. [homepage on the Internet] Euromonitor; 2020 [cited 2021 Mar 10]. Available from: https://www.euromonitor.com

21. DHL. Carbon calculator [homepage on the Internet]. DHL; 2020 [cited 2020 Jun 1]. Available from: http:www.dhl-carboncalculator.com/\#/scenarios

22. Department of Environmental Affairs. South Africa's 3rd Biennial update report to the United Nations Framework Convention on Climate Change. Pretoria: Government printer; 2019.

23. U.S. Environmental Protection Agency. Greenhouse gases equivalencies calculator [homepage on the Internet]. U.S. Environmental Protection Agency; 2020 [cited 2020 Jun 18]. Available from: https://www.epa.gov/energy/greenhouse-gasequivalencies-calculator

24. International Transport Forum. International freight and related $\mathrm{CO}_{2}$ emissions by 2050: A new modelling tool [homepage on the Internet]. Discussion Paper No. 2050: A new modelling tool [homepage on the Internet]. Discussion Paper No. https://www.itf-oecd.org/sites/default/files/docs/dp201421.pdf 
25. Intergovernmental Panel on Climate Change. Chapter 8. Reporting Guidance and Tables. In: Eggleston HS, Buendia L, Miwa K, Ngara T, Tanabe K, editors. Guidelines for national greenhouse gas inventories. Volume 1: General guidance and reporting. Japan: Institute for Global Environmental Strategies (IGES), 2006; p. 84.

26. Gouldson A, Sudmant A, Khreis H, Papargyropoulou E. The economic and social benefits of low-carbon cities: A systematic review of the evidence [homepage on benefits of low-carbon cities: A systematic review of the evidence [homepage on the Internet]. New Climate Economy; 2018 [cited 2020 Jun 6]. Available from: https://newclimateeconomy.report/workingpapers/wp-content/uploads/
sites/5/2018/06/CUT2018_CCCEP_final.pdf.

27. Department of Environmental Affairs. Freight shift from road to rail. Pretoria: Government printer; 2017.

28. Kaack LH, Vaishnav P, Morgan MG, Azevedo IL, Rai S. Decarbonizing intraregional freight systems with a focus on modal shift. Environ Res Lett. 2018;13:e083001. https://doi.org/10.1088/1748-9326/aad56c

29. Luxexcel. Ophthalmic products [homepage on the Internet]. Luxexcel; 2020 [cited 2020 Jun 20]. Available from: https://www.luxexcel.com/ophthalmicproducts

30. DHL. 3D Printing and the future of supply chains [homepage on the Internet]. DHL Customer Solutions \& Innovation; 2016 [cited 2020 Jun 13]. Available from: https://www.dhl.com/content/dam/dhl/global/core/documents/pdf/dhltrendreport-3dprinting.pdf
31. Burnson P. State of global logistics: Time for a reality check. Logist Manag. 2019;28-32.

32. Touratier-Muller N, Machat K, Jaussaud, J. Impact of French governmental policies to reduce freight transportation $\mathrm{CO}_{2}$ emissions on small- and medium-sized companies. J Clean Prod. 2019;215:721-729. https://doi.org/10.1016/j.jclepro.2019.01.052.

33. World Health Organization and Health Care Without Harm. Healthy hospitals, healthy planet, healthy people: Addressing climate change in health care setting [homepage on the Internet]. A discussion draft paper 2009. World Health Oranization; 2009 [cited 2021 Mar 10]. Available from: https://www.who.int/ globalchange/publications/healthcare_settings/en/

34. Storz MA. A practical guide for physicians and health care workers to reduce their carbon footprint in daily clinical work. Perm J. 2018;22:17-145. https://doi. org/10.7812/TPP/17-145

35. U.S. Environmental Protection Agency. Managing supply chain greenhouse gas emissions: Lessons learned for the road ahead [homepage on the Internet]. U.S Environmental Protection Agency; 2010. [cited 2020 Jun 18]. Available from: https://www.epa.gov/sites/production/files/2015-07/documents/managing supplychain_ghg.pdf

36. Anny Huang Y, Weber CL, Scott Matthews H. Categorization of Scope 3 emissions for streamlined enterprise carbon footprinting. Environ Sci Technol. 2009;43(22):8509-8515. https://doi.org/10.1021/es901643a 